\title{
Narrativas Audiovisuais, Patrimônio Cultural e Comunicação Pública: Oficina de Produção de Vídeos com Celular, em Igarassu/PE
}

\author{
Raphael de F. e Silva1, Gustavo H. O. de Almeida2, Thelma P. Alves3 \\ 1Universidade Federal de Pernambuco (UFPE) \\ 2Empresa Pernambuco de Comunicação (EPC) \\ 3Universidade Federal de Pernambuco (UFPE)
}

raphasilva07@gmail.com,gustavo.almeida@epc.pe.gov.br,tpanerai@gmail.com

\begin{abstract}
This article is inserted in the research group Media and intercultural Mediations of the EDUMATEC/UFPE, consisting of the description of a workshop carried out by the EPC (Pernambuco Communication Company), At the request of the Iphan, in the city of Igarassu/PE, aiming to educate the agents of popular culture, craftsmen and residents of the municipality, notions for audiovisual production with mobile, Using cultural heritage as a thematic and promoting a debate with public communication. This work has a qualitative approach, with a method based on a case study and a descriptive objective. data for this article come from participant observation and analysis of the videos produced.
\end{abstract}

Resumo. Este artigo está inserido grupo de pesquisa Mídias e Mediações Interculturais do EDUMATEC/UFPE, consistindo na descrição de uma oficina realizada pela EPC (Empresa Pernambuco de Comunicação), a pedido do Iphan, na cidade de Igarassu/PE, objetivando educar os agentes da cultura popular, artesãos e moradores do município, com noções para produção audiovisual com celular, utilizando o patrimônio cultural como temática e promovendo um debate com a comunicação pública. Este trabalho possui uma abordagem qualitativa, com método baseado em estudo de caso e objetivo descritivo. Os dados para este artigo vêm da observação participante e análise dos vídeos produzidos.

\section{Narrativas audiovisuais, patrimônio cultural e comunicação pública}

Em seu processo de formação, o sujeito inevitavelmente buscará um vislumbre do passado, estabelecendo essa relação a partir do seu local de fala, influenciado por suas experiências do presente. Esse diálogo possibilita o desenvolvimento de uma consciência histórica, atuando na construção identitária do indivíduo. Em todos os momentos da vida, da infância à fase adulta, nos deparamos com reflexões sobre nossa história, de modo que as ressignificações do passado, a partir do presente, contribuem 
fortemente na estruturação das nossas subjetividades políticas, religiosas, éticas e afetivas, entre outras.

Por sua vez, o acesso ao passado ocorre através de várias interfaces, como visitas a lugares históricos, museus, por meio das histórias contadas por nossos parentes mais velhos, filmes e, tradicionalmente, nos livros de História. Todas essas interfaces surgem como narrativas e é através delas que se manifesta o conhecimento histórico (RUSEN, 2002).

Costumeiramente, ao falarmos em narrativas, fazemos uma associação imediata com textos na escrita alfabética. Contudo, a organização da exposição em um museu obedece a uma narrativa, visando contar uma história aos visitantes. Também são narrativas as histórias contadas oralmente por nossos avós e os filmes, ficcionais ou documentais, que assistimos.

Portanto, fica fácil reconhecer como o contato com narrativas históricas desenvolvidas por terceiros pavimenta nossa formação. Não obstante, existe um potencial maior para produção de ressignificações acerca do passado quando os indivíduos conquistam a possibilidade de serem autores de suas próprias narrativas, viabilizando construções reflexivas sobre o passado. Para isso, contemporaneamente, contamos com diversos suportes à produção de narrativas, desde o tradicional texto escrito às linguagens proporcionadas pelo acesso da população aos meios de produção midiáticos.

Em tempos de popularização das Tecnologias Digitais de Informação e Comunicação (TDIC), vivemos a concretização da cultura digital, preconizada por autores como Lévy $(2003,2010)$ e Lemos (2005), na década de 1990. As tecnologias digitais mudaram drasticamente as formas de relação com nossos pares, além de ampliar o fluxo informacional, cultivando uma sociedade baseada na informação e mudando nossa relação com os meios de comunicação.

Nesse sentido, as tecnologias digitais provocam uma ruptura com o padrão até então estabelecido, em que as funções do emissor e do receptor das mídias eram sólidas, bem definidas. Na cultura digital, o espectador não mais se limita a assistir as produções midiáticas, passando a ocupar os espaços disponíveis no ciberespaço com conteúdos de sua própria autoria, disputando espaço com os que antes monopolizavam os meios de comunicação. Todo esse processo é catalisado pela ampla disponibilidade das TDICs móveis, como os atuais telefones celulares, capazes de produzir vídeos em alta definição.

Em meios às rupturas narrativas e midiáticas, situa-se a comunicação pública, dialogando com o direito humano da liberdade de expressão, o acesso à informação e a livre propagação de ideias e manifestações culturais, respeitando-se os direitos humanos. Suprindo lacunas geradas pelo desinteresse das emissoras comerciais em universos de menor audiência.

Surgida a partir dos preceitos da comunicação pública, a Empresa Pernambuco de Comunicação (EPC)1, através da emissora TV Pernambuco (TVPE), seu portal de notícias e suas redes sociais de internet, cumpre o papel de democratizar o acesso à 
informação jornalística e às manifestações culturais no estado de Pernambuco. Além disso, promove a participação da sociedade civil organizada através de conselhos administrativos. Viabilizando, também, a participação popular na programação, através de projetos como o TVPE Escola, no qual jovens de escola pública criam vídeos com celular para serem exibidos durante os intervalos.

Nesse contexto, emerge a oficina $O$ olhar cinematográfico acerca das narrativas da cultura popular: produção de vídeos utilizando telefone celular, ministrada pela EPC, a pedido do Instituto do Patrimônio Histórico e Artísitico Nacional (Iphan), tendo como local a Casa do Patrimônio do Iphan, em Igarassu, município pernambucano com vasto patrimônio histórico, sendo um dos primeiros núcleos de povoamento durante a colonização portuguesa no Brasil.

A oficina objetivou prover os agentes da cultura popular, artesãos e moradores do município com noções para produção audiovisual com celular. A partir dessa formação, o Iphan busca estimular o autorregistro audiovisual, possibilitando uma maior difusão das manifestações culturais e patrimônios culturais imateriais através das mídias sociais, como YouTube, além de ocupar a programação da TVPE, a partir da parceria com a EPC.

O presente artigo apresenta uma abordagem qualitativa, com método baseado em estudo de caso e com objetivo descritivo, detém-se em relatar a experiência vivenciada durante a oficina, baseando-se na observação participante dos educadores, somando-se a uma análise dos vídeos produzidos pelos estudantes.

\section{Referencial}

Os conceitos de patrimônio passaram por uma longa ressignificação ao longo do século passado. De acordo com Fernandes (1993), a partir do decreto lei $\mathrm{n}^{\circ} 25$ de 1937, estipulou-se que o Patrimônio Histórico e Artístico brasileiro seria composto por bens móveis e imóveis cuja conservação fosse de interesse público, vinculando-se aos fatos memoráveis e históricos da nação.

Contudo, o avanço teórico e metodológico das Ciências Sociais, na segunda metade do século XX, fez emergir um novo conceito para patrimônio histórico e artístico, provocando uma ruptura com a própria nomenclatura até então utilizada. Nesse sentido, passou-se à denominação de Patrimônio Cultural, abrangendo, sobretudo, uma gama maior de manifestações culturais e artísticas.

A partir do novo conceito de Patrimônio Cultural, surgem novas abordagens sobre os bens culturais, abarcando várias manifestações materiais e imateriais. Os bens culturais são "toda produção humana de ordem emocional, intelectual e material, independente de sua origem, época ou aspecto formal, bem como a natureza, que propiciem o conhecimento e as consciência do homem sobre si mesmo e sobre o mundo que o rodeia" (GODOY, 1983, p.72 apud FERNANDES, 1993, p.268). Portanto, partindo-se dessa conceitualização, abre-se um leque maior à classificação dos patrimônios culturais, extrapolando os limites dos prédios históricos e dialogando com as diversas manifestações da cultura popular que permeiam a sociedade brasileira.

Para Fernandes (1993), essa mudança de concepção impacta diretamente na relação do patrimônio com a educação e o exercício da cidadania. Nesse sentido, faz-se necessária a inserção dos reconhecidos patrimônios culturais nos contextos 
educacionais, desde a educação básica formal aos ambientes de educação complementar, fazendo emergir a educação patrimonial. Fomentando a construção do cidadão em diálogo com sua história, valorizando e promovendo a continuidade das manifestações artísticas entre gerações.

Assim, podemos afirmar que educação patrimonial é um forte catalisador ao desenvolvimento da consciência histórica (RUSEN, 1992; 1996), que, por sua vez, consiste em uma mudança cognitiva acerca das relações com o passado, sendo uma

\begin{abstract}
mudança estrutural na consciência histórica. A aprendizagem histórica implica mais que um simples adquirir de conhecimento do passado e da expansão do mesmo. Visto como um processo pelo qual as competências são adquiridas progressivamente, emerge como um processo de mudança de formas estruturais pelas quais tratamos e utilizamos a experiência e conhecimento da realidade passada, passando de formas tradicionais de pensamento aos modos genéticos. (RUSEN, 1992, p.27)
\end{abstract}

De acordo com Rusen (1992;1996), existem quatro formas de consciência histórica: tradicional, baseada na reprodutibilidade dos fatos históricos consolidados; exemplar, quando a história é usada para exemplo de conduta moral e ética; crítica, quando há oposição à história tradicional consolidada; e genética, quando nos tornamos autores na escrita de nossa própria história.

Para Rusen (1992; 2006), a consciência histórica, em qualquer das suas quatro formas, manifesta-se através das narrativas históricas. Neste sentido, emerge um diálogo com Brunner (1991;1997), para quem a narrativa é a forma como organizamos nossas experiências e pensamentos:

Nós organizamos nossa experiência e nossa memória de acontecimentos humanos principalmente na forma de narrativas: história, desculpas, mitos, razões para fazer e para não fazer, e assim em diante. A narrativa é uma forma convencional, transmitida culturalmente e restrita por cada nível de domínio individual de domínio e por seu conglomerado de dispositivos protéticos, colegas e mentores. (BRUNER, 1991, p. 4)

As concepções de Fernandes (1993), Rusen (1992; 2006) e Brunner (1991;1997) convergem diretamente com a proposta da oficina ministrada pela EPC, a pedido do Iphan, na qual buscamos prover os cidadãos de Igarassu, com técnicas de produção de vídeos com celular, para que pudessem produzir suas próprias narrativas relacionadas aos patrimônios culturais do município, estabelecendo uma relação com a comunicação pública e as novas formas de participação midiática proporcionadas pelas TDICs.

Antes de avançar, faz-se necessária a contextualização da existência da EPC no âmbito do conceito de comunicação pública, elemento fundamental ao movimento de democratização do acesso ao rádio, televisão e demais mídias contemporâneas.

Para Bucci,

Universidades ou escolas públicas justificam-se porque atendem o direito à educação. Hospitais públicos, por garantir o acesso do cidadão à saúde e aos tratamentos e cuidados a que tem direito. Uma emissora pública existe porque as pessoas têm direito (como autoras, agentes ou espectadoras) à informação jornalística, ao conhecimento e às manifestações culturais (BUCCI, 2010, p. 05, grifo nosso) 
Como observamos existe um debate constitucional urgente sobre a necessidade da comunicação pública em nossa sociedade, surgindo como instrumento de participação popular, promovendo a inclusão midiática da população sem espaço na mídia comercial. Além de viabilizar a participação através da autoria.

Como afirmado por Leal Filho (2019):

\begin{abstract}
Não há no Brasil, infelizmente, o enraizamento da ideia da importância do que é a comunicação pública. A nossa história de rádio e de televisão foi toda construída em cima da televisão comercial, então a população nem tem ideia de que uma outra forma de comunicação é possível. Ela é uma comunicação diferente da comunicação comercial porque permite através de vários mecanismos, conselhos, audiências, que a sociedade participe desse processo. (LEAL FILHO, 2019, s/n)
\end{abstract}

Contextualizada nesse debate, situa-se a EPC, uma empresa pública do estado de Pernambuco, sendo responsável pela comunicação pública, principalmente através de sua emissora de televisão, TVPE, operando a partir dos preceitos expostos por Bucci (2010) e Leal Filho (2019). Funciona como espaço de participação da sociedade civil organizada, através de conselhos administrativos, proporcionando espaço às manifestações culturais populares e atingindo universos restritos de audiência, que não teriam espaço na mídia comercial.

Visando ampliar a participação popular através da autoria, foi criado o TVPE Escola (SILVA, PEREIRA e FAGUNDES, 2018), com a proposta de oferecer educação audiovisual aos alunos da rede pública estadual, através de oficinas regulares de audiovisual, objetivando a produção de vídeos para a exibição na programação diária da TVPE, em programas e intervalos, bem como nas redes sociais e canais na internet. Para isso, as oficinas buscam aproveitar o potencial das TDICs móveis, principalmente os telefones celulares, para produção de vídeos em alta definição.

Para a elaboração das oficinas, o TVPE Escola baseou-se na experiência desenvolvida pelo Inventar com a Diferença (MIGLIORIN et al., 2016), projeto iniciado em 2014, por professores da UFF/RJ, sistematizando experiências e orientações didáticas para um diálogo entre educação, cinema e os direitos humanos, num material didático de livre distribuição e adoção pelos interessados em desenvolver experimentações com audiovisual no campo educacional.

A utilização do Inventar com a Diferença como base do TVPE Escola possibilita o intercâmbio de linguagens entre o audiovisual cinematográfico e o televisivo, favorecendo experimentações a partir das duas linguagens, nas escolas onde o projeto atuou.

Ainda, o TVPE Escola está alinhado com as concepções de Martín-Barbero (2014) sobre as possibilidades oriundas da relação entre educação e comunicação. Para este autor

a crítica indispensável, tanto dos conteúdos como das formas de sedução dos meios audiovisuais, só será válida e socialmente eficaz quando a escola for capaz de inserir essa crítica em um projeto de mudança educativa de envergadura cultural. Entendo como tal, em primeiro lugar, um projeto que recoloque a ideia de cultura com a qual a escola trabalha em nossos países para que comece a reconhecer as ciências e tecnologias, tanto como dispositivos de produtividade como de transformação dos modos de perceber, de saber e de sentir. O que implica incorporar as novas tecnologias de 
comunicação e informação como "tecnologias intelectuais", isto é, como estratégias de conhecimento e não como meros instrumentos de ilustração ou difusão (MARTÍN-BARBERO, 2014, p. 56)

Nesta relação entre educação e comunicação, a escola passa a ser concebida como um espaço onde as mídias devem ser problematizadas, viabilizando um consumo crítico dos discursos acessados pelos estudantes, provendo-os de competências para a compreensão dos signos lançados pelos meios audiovisuais.

Martín-Barbero (2014) nos alerta para a necessidade de reconhecer as possibilidades presentes nas novas tecnologias digitais, rompendo com a concepção de que são meros instrumentos de ilustração de difusão, clamando por uma utilização ativa dessas tecnologias, possibilitando a autoria audiovisual nas escolas. O debate levantado pelo autor dialoga contemporaneamente com as concepções de cultura da convergência.

Para Jenkins (2008, 2015), a cultura digital presente em nossa sociedade modificou a relação da sociedade com as mídias. A popularização das TDICs propiciou o abandono, por parte dos expectadores, da zona de conforto gerada pelo consumo passivo das mídias, fazendo emergir uma cultura da convergência midiática. Nesse contexto, surge a demanda por participação, seja sob a forma de interações mais simples até as que envolvem poderes decisórios sobre as mídias, culminando com o exercício da autoria pelos que antes eram apenas espectadores.

É nesse momento de convergência dos meios de comunicação que está inserida a oficina $O$ olhar Cinematográfico Acerca das Narrativas da Cultura Popular: produção de vídeos utilizando telefone celular, ministrada pela EPC, a pedido do Iphan, na cidade de Igarassu, com base nas experiências desenvolvidas anteriormente no âmbito do projeto TVPE Escola. Deste modo, o debate entre educação, comunicação pública e patrimônio cultural favorece o desenvolvimento de uma consciência histórica genética, aproveitando o potencial de criação audiovisual das TDICs e promovendo um intercâmbio entre as linguagens audiovisual televisiva e cinematográfica.

\section{Metodologia}

Este artigo apresenta uma abordagem qualitativa com método baseado em estudo de caso e com o objetivo de ser um estudo descritivo.

Em Creswell (2010), encontramos uma definição sobre pesquisa qualitativa:

A pesquisa qualitativa ocorre em um cenário natural. O pesquisador
qualitativo sempre vai ao local (casa, escritório) onde está o participante para
conduzir a pesquisa. Isso permite ao pesquisador desenvolver um nível de
detalhes sobre a pessoa ou sobre o local e estar altamente envolvido nas
experiências reais dos participantes. (CRESWELL, 2010, p. 186)

Em relação ao método de estudo de caso, utilizamos as diretrizes de Yin (2015), para quem o estudo de caso surge a partir do problema de pesquisa proposto. Portanto, "quanto mais suas questões procurarem explicar alguma circunstância presente (por exemplo, "como" ou "por que" algum fenômeno social funciona), mais o método do estudo de caso será relevante" (YIN, 2015, p.4).

Nesse sentido, acreditamos que o estudo de caso, com caráter descritivo, contempla a abordagem deste artigo, no qual descrevemos as vivências dos participantes da oficina juntamente a uma análise das suas produções audiovisuais. 


\section{A oficina}

Segundo o edital do Iphan, o projeto previa:

a realização de oficina de cinema direcionada a agentes culturais, mestres e brincantes da cultura popular interessados em fazer filmes que documentem sua perspectiva, seu cotidiano e/ou vida e obra de mestres da cultura popular do município de Igarassu e cidades adjacentes.” (IPHAN, 2018, s/p).

A oficina foi ministrada entre os dias 25 e 29 de março de 2019, na Casa do Patrimônio do Iphan em Igarassu, diariamente das 9h às 16h, totalizando uma cargahorária total de $30 \mathrm{~h}$.

A oficina contou com 33 participantes, constituindo-se de um público diversificado, com faixa etária entre 15 e 60 anos, contemplando representantes de diversas áreas de atuação tais como: artesãos bonequeiros, dançarina, pesquisador do patrimônio histórico, músico e estudantes de ensino médio.

Durante o primeiro dia, pela manhã, foram abordadas as relações entre mídia, comunicação pública, cultura popular e cinema. À tarde, ocorreu uma aula expositiva acerca de técnicas básicas de produção audiovisual.

No segundo dia, foi realizada uma aula de campo, ocasião em que foram visitados os ateliês dos artesãos escultores Roberto Vital e Moizés Vital. Durante a visita, os participantes da Oficina puderam pôr em prática as técnicas de captação audiovisual com telefone celular, gravando entrevistas com os artistas.

No terceiro dia, no turno da manhã, os participantes tiveram contato com técnicas básicas para edição de vídeos, por meio de aulas práticas com o software Adobe Premiere Pro. Os participantes praticaram edição de vídeos a partir do material produzido no dia anterior.

Durante o turno da tarde, ainda no terceiro dia, foi realizada uma visita à residência de Lia do Coco, mestra do Coco de Roda, em Igarassu, quando os estudantes puderam captar material audiovisual para compor um filme sobre essa importante personagem da cultura do município.

No quarto dia de Oficina, no turno da manhã, os estudantes realizaram uma entrevista com a artesã Leandra Lawless, confeccionadora de joias e adornos com escamas de peixe. Ainda pela manhã, produziram um vídeo a partir da performance da bailarina Janaina Santos.

A tarde da quinta-feira e a manhã da sexta-feira foram dedicadas à finalização dos filmes produzidos pelos participantes. E durante à tarde do último dia foi realizada uma culminância com exibição de todos os vídeos produzidos durante a oficina.

Ao fim da oficina, contabilizamos cinco filmes produzidos pelos participantes, com predominância do formato documental em quatro das produções. A quinta tratou de uma abordagem experimental, dando origem ao vídeo-dança "Frevo na Ladeira".

Abaixo segue um frame de cada produção, com seu respectivo hiperlink: 


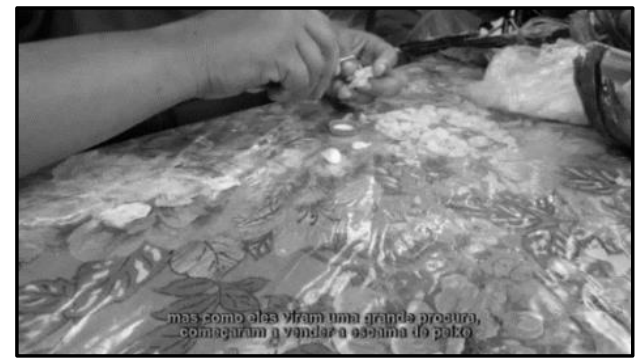

Figura 1: Artesã Leandra Lawless, disponível em https://youtu.be/F6R30anl8ho

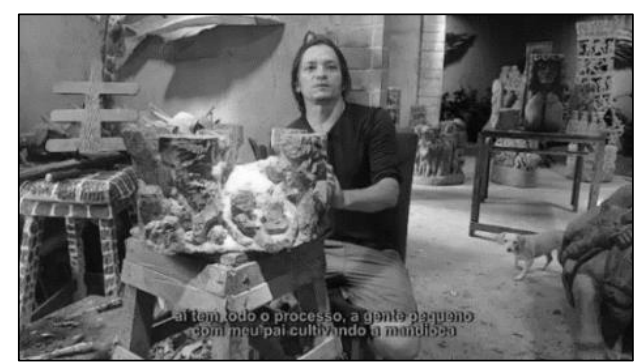

Figura 3: Artesão Roberto Vital, disponível em https://youtu.be/yb1legvNBKE

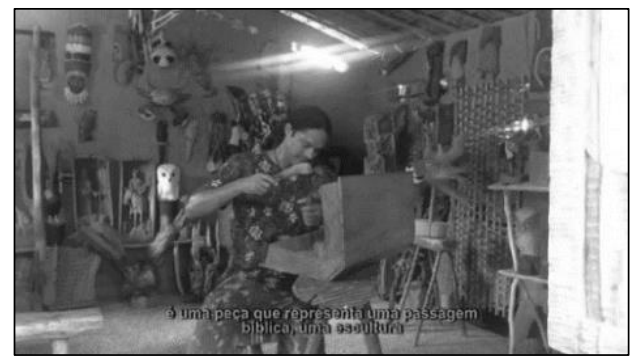

Figura 2: Artesão Moizés Vital, disponível em https://youtu.be/oqa0BonMciA

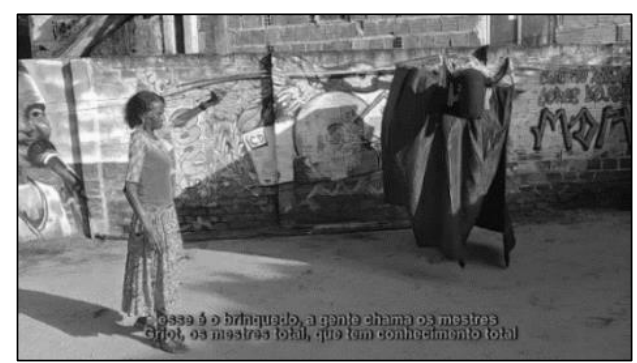

Figura 4: Lia de Igarassu, disponível em https://youtu,be/eal5TjiMmCY

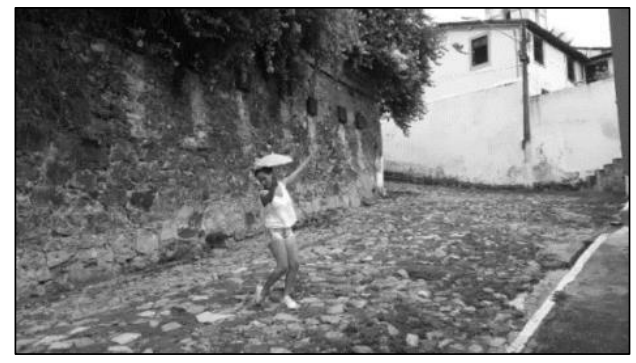

Figura 5: Frevo na Ladeira, disponível em https://youtu.be/kvLegFG8ocw

A partir das imagens, podemos observar a diversidade relacionada ao patrimônio cultural registrada pelos participantes da oficina. Três dos produtos abordaram artesãos da cidade de Igarassu - Leandra Lawless, Roberto Vital e Moisés Vital - os quais falaram de suas artes, inspirações e histórias de vida, proporcionando um novo olhar acerca de artesãos residentes em Igarassu, sem, contudo, habitar o imaginário dos cidadãos igarassuenses.

Logo, podemos afirmar que a oficina cumpriu um importante papel ao desvelar um patrimônio cultural oculto aos próprios moradores da cidade, servindo à construção de uma representação audiovisual acerca desses artistas, possibilitando que esse patrimônio cultural seja valorizado e difundido através da comunicação pública, representada aqui pela EPC/TVPE, estando presente também no ciberespaço, através das mídias e redes sociais de internet. 
Seguindo a mesma linha, o filme produzido sobre Lia de Itamaracá cumpre a mesma função de trazer à tona uma artista popular, mestra do coco de roda, residente em Igarassu há décadas, que ainda não ocupa um espaço devido e merecido como patrimônio cultural vivo.

Por sua vez, o vídeo Frevo na Ladeira, possibilitou um diálogo entre as linguagens do audiovisual e da dança, retratando o patrimônio histórico a partir de uma performance de frevo em uma das ladeiras do sítio histórico de Igarassu.

A partir da análise dos vídeos produzidos durante a oficina, constatamos o potencial dos telefones celulares contemporâneos como instrumentos que viabilizam a autoria audiovisual, com baixo custo. Podemos afirmar que, nestas situações, estes dispositivos estão à altura dos instrumentos profissionais de produção audiovisual televisivo e cinematográfico, abrindo uma valiosa oportunidade para que a linguagem audiovisual possa ser utilizada em processos educativos.

No caso abordado, as potencialidades foram exploradas para o desenvolvimento de um conhecimento crítico e autoral em relação ao patrimônio cultural de Igarassu, fazendo com que os estudantes pudessem elaborar narrativas audiovisuais sobre a cultura popular, ressignificando a relação dos sujeitos com os artistas, artesãos, saberes populares e com a própria arquitetura da cidade histórica de Igarassu.

\section{Considerações finais}

A experiência relatada demonstra a potencialidade das TDIC em relação à produção de narrativas audiovisuais, tendo o patrimônio cultural como tema, servindo para ressignificar as relações dos indivíduos com as manifestações culturais que os rodeiam, contribuindo fortemente para o registro e/ou autorregistro dos agentes de cultura popular, principalmente aqueles não pertencentes ao patrimônio cultual institucionalizado por autoridades estatais competentes, como o Iphan.

Ainda, é notório como as TDIC favorecem a participação autoral na comunicação pública, tornando possível ao cidadão utilizar instrumentos de seu alcance cotidiano, para ocupar a programação de uma TV pública com obras audiovisuais de boa qualidade técnica e em alta definição. Contudo, faz-se necessário o aprofundamento sobre a experiência relatada neste artigo, principalmente no que tange aos limites e possibilidades de aprendizagem acerca do patrimônio cultural, decorrentes da utilização das TDICs sob o viés da autoria audiovisual. O mesmo aprofundamento é imprescindível para investigar como a participação dos indivíduos, principalmente em idade escolar, na comunicação pública, favorece a aprendizagem em outras áreas de conhecimento e, também, na sua formação, visando o exercício pleno da cidadania e obedecendo a diretrizes éticas e de respeito aos direitos humanos.

\section{Referências}

BARBERO, Jose Martin. (2014) A Comunicação na Educação. Tradução por Maria I. V. de Lopes e Dafne Melo. São Paulo: Contexto.

BRUNER, Jerome. (1991) A Construção Narrativa da Realidade. Tradução: Waldemar Ferreira Netto. IN: Critical Inquiry, 18(1), pp. 1-21. Disponível em: http://www.academia.edu/4598706/BRUNER_Jerome.A_constru\%C3\%A7\%C3\% A3o_narrativa_da_realidade Acesso em: 15 jan 2018 
. (1997) Atos de Significação. Porto Alegre: Artes Médica.

BUCCI, Eugênio. (2010) É possível fazer televisão pública no Brasil? IN: Novos Estudo, nº8, nov.

FERNANDES, José R. Oriá. (1993) Educação patrimonial e cidadania: uma proposta alternativa para o ensino de História. IN: Revista Brasileira de História, V.13, n. 25/26, p.256-276, set. 92/ago.93

IPHAN. (2018) Projeto Básico para Oficina de cinema na casa do patrimônio / ipha/n em igarassu (pe): o olhar cinematográfico acerca das narrativas da cultura popular. IN: Licitação Convite 02/2018. Igarassu: IPHAN.

JENKINS, Henry. (2008) Cultura da convergência. São Paulo, Editora Aleph.

(2015) As competências necessárias na cultura dos novos media. In:

Brites, Maria José; Jorge, Ana \& Santos, Sílvio Correia. (Editores). Metodologias

Participativas: Os media e a educação. Covilhã: LabCom Books. Disponível em: http://www.labcom-ifp.ubi.pt/ficheiros/20150629-

2015_10_metodologias_participativas.pdf

LEAL FILHO, Laurindo. (2019) Desafios e Perspectivas da Comunicação Pública no Nordeste. IN: Palestra ministrada durante no $\mathbf{1}^{\mathbf{0}}$ Diálogos EPC/TVPE em 11 jun. 2019. Recife.

LEMOS, André. (2007) Ciberespaço e Tecnologias Móveis. Processos de Territorialização e Desterritorialização na Cibercultura. Disponível em: http://www.facom.ufba.br/ciberpesquisa/andrelemos/territorio.pdf. Acesso em: 03 maio 2017.

LÉVY, Pierre. (2003) A revolução contemporânea em matéria de comunicação. In: MARTINS, F. M.; SILVA, J. M. da. Para navegar no século XXI. Tecnologias do imaginário e cibercultura. 3.ed. Porto Alegre: Sulina/Edipucrs.

(2010) As tecnologias da inteligência: o futuro do pensamento na era da informática. São Paulo: Editora 34.

MIGLIORIN, Cezar. et al. (2016) Cadernos do Inventar: cinema, educação e direitos humanos. Niterói: EDG.

RUSEN, Jorn. (1992) El desarrollo de la competência narrativa en el aprendiaje histórico. Una hipótesis ontogenética relativa a la conciencia moral. IN: Revista Propuesta Educativa, Buenos Aires, Ano 4, n.7, p.27-36. oct.

. (1996) Narratividade e objetividade nas ciências históricas. IN: Textos de História. Brasília, v.4, n.1, p.75-102.

SILVA, Raphael de F e; PEREIRA, Cynthia G. F.; FAGUNDES, Valéria P. (2018) TVPE Escola: participação de estudantes de ensino médio na comunicação pública através da autoria audiovisual. IN: Anais do $7^{\circ}$ EPEP. 